\title{
The Effectiveness of Different Levels of Activation in Higher Education
}

\author{
Figas, Paula ${ }^{\text {a }}$; Sailer, Michael ${ }^{\mathrm{b}}$; Hagel, Georg ${ }^{\mathrm{a}}$; Sailer, Maximilian ${ }^{\mathrm{b}}$ \\ ${ }^{a}$ Faculty of Computer Science, Kempten University of Applied Sciences, Germany \\ ${ }^{\mathbf{b}}$ Faculty of Psychology and Educational Sciences, LMU Munich, Germany
}

\begin{abstract}
Although there are several empirical studies about active learning in higher education, there are some open research questions. Especially, it appears to be relevant to find out what type of activity (active, interactive and constructive) has a positive effect on the learning result of participants in task-based activities. In order to answer this question an experimental study was conducted with students in German higher education $(N=50)$. The results do not show a significant difference between active, interactive and constructive activities on learning performance in task-based learning. But all groups have benefited from the classroom activities according to the test results.
\end{abstract}

Keywords: active learning; task-based learning; higher education; experimental study 


\section{Introduction}

Active learning has received a great deal of attention in higher education (e.g. Wanner 2015; Virtanen, Niemi and Nevgi 2017). This article deals with this approach and presents an experimental study about the role of different types of activation. The first part gives a brief overview of previous research findings on the topic of active learning in higher education. The second part is about the effectiveness of different levels of activation by looking at the results of an experimental examination. The last part summarizes the key findings and outlines future research needs.

\section{Active Learning in Higher Education}

The question of the effectiveness of active learning begins with the approach's fundamental ideas. Prince (2004) defines it as any instructional approach that engages students in learning, for example collaborative learning, cooperative learning or problem-based learning. According to Freeman et al. (2014) "active learning engages students in the process of learning through activities and/or discussions in class, as opposed to passively listing to an expert". Watkins, Carnell and Lodge (2007) stated that active learning includes three dimensions of learning: behavioral, cognitive and social. Although it remains challenging to study the impact of active learning (Prince 2004), studies show that it does positively impact students' learning (e.g. Hyun, Ediger and Lee 2017; Prince 2004). There are several ways of active learning; one possibility is to stimulate students with tasks-based activities (Wiggins et al. 2017). Task-based learning in foreign language learning shows for example how tasks can serve as an instrument to enable communicative interactions (Ellis 2009). Michelene Chi separates active learning into three types: active, constructive and interactive (Chi 2009; Chi and Wylie 2014). Being active simply means "doing something physically" (Chi 2009, p.77), for example through repeating or rehearsing. Constructive behaviors can be described as those in with students "produce additional externalized outputs or products beyond what was provided in the learning materials" (Chi and Wylie 2014, p.221), for example through generating hypotheses or reflecting out-loud. Finally, being interactive means dialoguing and creating processes, for example through "defending and arguing a position in dyads or small group[s]" (Chi and Wylie 2014, p.221). According to Chi, interactive activities are collaborative, creating processes in which all students' contributions are taken into consideration. Chi examined and interpreted experimental studies conducted within the science of learning to find out whether her conceptual division could be identified in practice. She concluded that interactive activities are generally more effective than constructive activities which, in turn, are better than active activities. All three types of activities support learning better than passive methods (Chi 2009; Chi and Wylie 2014). Chi reduces the relationship between the activities in the ICAP hypothesis: 
"interactive $>$ constructive $>$ active $>$ passive" (Chi 2009). In summary, it can be stated that the degree of participation evoked by the activities can turn out to be very different. Active learning is an umbrella term which implies different versions of cognitive processing and visible behavioral expressions. It should be critically noted that it cannot be assumed that all students always display an identical degree of activity. An educator's intention of initiating active, constructive or interactive activities will not necessarily result in the corresponding activity that all learners engage in. Students in an interactive setting can still be passive by not engaging in the intended activities.

\section{Experimental study}

Research shows that active learning does positively impact students' learning (e.g. Hyun, Ediger and Lee 2017; Prince 2004). However, the role of different types of activation in the same task-based learning situation has barely been investigated so far. This leads to the following research question: what type of activation has a positive effect on the learning result of students with task-based activities? A pilot study with an experimental design was conducted to answer this research question. The study aims to examine parts of the ICAP hypothesis in more detail. It shall be examined to what extent the use of activities creates more efficient joint learning time and to what extent this can be recognized in the learning result. In particular, it will be examined what effects specific variations of the type of activation for performing instructional tasks have on the participants' learning results.

\subsection{Research design}

For the empirical experimental study, a pre-post control group design was chosen with the dependent variable (DV) "learning success". The learning success, operationalized in 20 questions of a declarative knowledge test, was measured immediately before (pre-test) and after completion of the learning unit (post-test). A pre-post control group design establishes before and after value which achieved by an experimental group in the examination. Since the control group does not run through the treatment, both inter-individual (between the groups) and intra-individual (within the experimental group) differences can be ascribed to the treatment, insofar as all possible confounding variables have been isolated.

\section{Table 1: Research design}

\begin{tabular}{|c|c|c|c|c|}
\hline $\begin{array}{l}\text { Pre- } \\
\text { Test }\end{array}$ & $\Rightarrow$ & $\begin{array}{l}\text { - Experimental group: interactive activity } \\
\text { - Control group 1: constructive activity } \\
\text { - Control group 2: active activity }\end{array}$ & $\Rightarrow$ & $\begin{array}{l}\text { Post- } \\
\text { Test }\end{array}$ \\
\hline
\end{tabular}


The major advantage of this design is that differences in the research results of pre- and post-tests can be explained by the intervention. A disadvantage that must be acknowledged is that the recognizable differences can perhaps be ascribed to the pre-test. Different treatment conditions are created for the independent variable (IV). The independent variable "type of activation" is three-tiered. Through a simple randomization, the participants are allocated to the various conditions. During the learning unit, a complex learning task is given to the students. The tiers of the independent variable differentiate between an experimental group which receives the treatment, a control group 1, and a control group 2. The groups vary in the degree of activity (interactive, constructive, and active) while solving the same application tasks during the learning unit. To ensure comparability, the lecturer is given a detailed introduction to the instructional procedure. Aside from the defined behaviors, it was necessary for the lecturer to possess well-founded professional competence. An overview of the research design is shown in table 1.

- The conditions in the experimental group aim to approximate the idea of "interactive activity". That means, during the performance of the task the focus lies on group work and dialoguing. The lecturer assumes a very active role, gives specific instructions, and encourages students to discuss with each other and to integrate separate contributions in the task process.

- The conditions of control group 1 aim to simulate the idea of "constructive activity". The lecturer encourages students to "contain new content-relevant ideas that go beyond the information given" (Chi 2009, p. 78): The lecturer instructs the participants to individually solve the tasks. In contrast to the experimental group, he acts more passively and does not stimulate discussions. Besides, he does not proactively monitor the processes, but instead lets the students determine the procedure themselves.

- The control group 2 simulates the idea of "active activity" according to Chi. The lecturer only introduces the learning tasks to the students, but neither engages any discussion nor supports group work. Students can solve the task by using existing learning materials. The lecturer at no time functions as a point of contact during the attendance time, but instead leaves the students to work through the problems independently.

Following this joint learning time, the declarative knowledge test consisting of 20 questions is taken again as post-test. The internal consistency of the test (pre and post), calculated via the Kuder-Richardson Formula, which is used for dichotomous items, shows a value of KR$20=0.70$ for the pre-test and a value of $\mathrm{KR}-20=0.75$ for the post-test. Based on the results, a satisfactory internal consistency can be assumed. 


\subsection{Results}

In total, 50 bachelor students studying Educational Science in a German University took part in the study, divided into the experimental group $(n=19)$, control group $1(n=14)$, and control group $2(n=17) .96 \%$ of the students are female and only $4 \%$ male, which can be ascribed to the gender-related composition of the degree. In order to answer the research question, an ANCOVA was conducted in SPSS with the three-tiered group variable "type of activation" with the manifestations experimental group (interactive activity), control group 1 (constructive activity), and control group 2 (active activity) as a fixed factor and the variable "knowledge test result" (post) as the dependent variable. Since the same knowledge test was already used as the pre-test before the intervention, the variable "test result" (pre) is used as a control variable and integrated into the model as a covariate. With this analysis, the results of the post-test are examined to determine whether differences between the three groups are recognizable, whereby the results of the pre-test are controlled (Field 2009). No predominant role is attributed to measuring the growth or changes. By controlling for the covariate alone aims, to determine the "pure" effect of the treatment on the post-test results, and also, to partial out the effect of the pre-test. By applying an analysis of covariance, the influence exerted by the control variable on the dependent variable is neutralized (Bortz 2005). This is related to the structure of the method, since the analysis of covariance combines ANOVA and regression models. The regression model calculates the partial influence of the control variable on the dependent variable. Therefore the within-group error variance will be reduced (Bortz 2005; Field 2009). The requirements for conducting an ANCOVA were met. From the descriptive results (see table 2), it becomes clear that the experimental group shows the highest $(\mathrm{M}=12.68, \mathrm{SD}=4.08)$ and control group 2 the lowest mean value $(\mathrm{M}=8.59, \mathrm{SD}=4.29)$. The difference between the experimental group (interactive activity) and control group 1 (active activity) is very small $(\Delta=0.97)$.

Table 2: Mean values and SD post-test

\begin{tabular}{|llll|}
\hline Groups & $\mathrm{M}$ & $\mathrm{SD}$ & $\mathrm{N}$ \\
\hline Experimental group & 12.68 & 4.08 & 19 \\
Control group 1 & 11.71 & 3.69 & 14 \\
Control group 2 & 8.59 & 4.29 & 17 \\
Total & 11.02 & 4.36 & 50 \\
\hline
\end{tabular}

It shows that the covariate has a significant influence on the variable "test result post-test" $(F(1.46)=37.41, p<0.05, r=0.67)$. The effect size $\mathrm{r}$ is won from the t-value of the parameter estimation (Rosnow and Rosenthal 2005). In contrast, no significant group differences of the variable "type of activation" could be observed regarding the learning 
result of the post-test $\left(F(2,46)=0.42, p>0.05\right.$; partial $\left.\eta^{2}=.02\right)$. The results exemplify that a high proportion of variance of the knowledge test (post) can be explained through the pre-test (partial $\eta^{2}=.45$ ). The differing test results (post) cannot be explained by the variation of type of activation. Although the experimental group achieved the best results on average in the knowledge test, this is not proven to be significant. Nonetheless, the result is not proof that the type of activity within the framework of the attendance phase is unimportant. What is noticeable is that all groups improve compared to the first measurement (pre). The experimental group was able to increase its result by an average of 1.94 points. Control group 1 also achieved an increase by 1.78 points compared to the pretest, as did control group 2, improving its pre-test results by 1.88 points. Even though these improvements are not significant, they do attest to a supportive learning effect in application-oriented tasks which consolidate the subject matter and enable a new way of accessing the subject. It should also be taken into consideration that both tests examined declarative knowledge, while the attendance phase aimed for application and consolidation of knowledge. It can be assumed that the participants developed a much more in-depth understanding of the subject than depicted by the knowledge test.

\section{Conclusion}

The results of the study show that all groups - interactive, constructive and active - were able to register a knowledge growth after the active learning unit, but that the differences between the groups were not significant. Obviously, active learning involved practicing together undeniably leads to an increase in knowledge. The "how" of practicing does not seem to be crucial. This supports the assumption that not only the degree of activation during a learning unit is important for students' learning success, as the literature frequently postulates (Bishoph and Verleger 2013), but that other factors, such as didactically meaningful assignments, also play a key role. Besides, it should be pointed out that the study only measured declarative knowledge. In this respect, it would be interesting to conduct another study which observes procedural knowledge components in a targeted way and to follow the question of how these can be developed through the design of the attendance phase. The non-significant difference between the groups could, however, also be attributed to the experimental arrangement. The relationship between study power and the veracity of the resulting finding should be shortly addressed. The finding of nonsignificant results may be caused by the small sample size and therefore low statistical power. Nonetheless, the results of the study offer many follow-up possibilities for further studies. Additional research needs also exist for larger studies that include more participants and span a longer period of time. 


\section{References}

Bishop, J.L. \& Verleger, M.A. (2013). The flipped classroom: A survey of research. In American Society for Engineering Education (ed.), 12th Annual Conference \& Exposition. Atlanta.

Bortz, J. (2005). Statistik für Human- und Sozialwissenschaftler. Berlin et. al: Springer.

Chi, M.T. (2009). Active-constructive-interactive: A conceptual framework for differentiating learning activities. Topics in Cognitive Science, 1, 73-105.

Chi, M.T., \& Wylie, R. (2014). The ICAP framework: Linking cognitive engagement to active learning outcomes. Educational Psychologist, 49(4), 219-243.

Ellis, R. (2009). Task-based language teaching: Sorting out the misunderstandings. In: International Journal of Applied Linguistics, 19(3), 221-246.

Field, A. (2009). Discovering statistics using SPSS. London: Sage.

Freeman, S., Eddy, S.L., McDonough, M., Smith, M.K., Okoroafor, N., Jordt, H., \& Wenderoth, M.P. (2014). Active learning increases student performance in science, engineering, and mathematics. Proceedings of the National Academy of Sciences USA, 111(23), 8410-8415.

Hyun, J.; Ediger, R., \& Lee, D. (2017). Students' satisfaction on their learning process in active learning and traditional classrooms. International Journal of Teaching and Learning in Higher Education, 29(1), 108-118.

Prince, M. (2004). Does active learning work? A review of the research. Journal of Engineering Education, 93(3), 223-231.

Rosnow, R.L., \& Rosenthal, R. (2005). Beginning behavioral research: A conceptual primer. Englewood Cliffs, NJ: Pearson/Prentice Hall.

Virtanen, P.; Niemi, H.M. \& Nevgi, A. (2017). Active learning and self-regulation enhance student teachers' professional competences. Autralian Journal of Teacher Education, 42(12), 1-20.

Wanner, T. (2015). Enhancing student engagement and active learning through Just-in-time teaching and the use of PowerPoint. International Journal of Teaching and Learning in Higher Education, 27(1), 154-163.

Watkins, C., Carnell, E., \& Lodge, C. (2007). Effective learning in classrooms. London: Sage.

Wiggins, B.L., Eddy, S. L., Grundspan, D.Z., \& Crowe, A.J. (2017). The ICAP active learning framework predicts the learning gains observed in intensely active classroom experiences. American Educational Research Association Open, 3(2), 1-14. 